\author{
Mauricio F. Rojas GómEz
}

\title{
LA CIUDAD COMO AGENTE MORALIZADOR: LA POLICÍA Y LA CIUDAD DE CONCEPCIÓN (CHILE), 1850-1880**
}

\begin{abstract}
RESUMEN
Este trabajo busca conocer cómo la adopción del modelo liberal de desarrollo y el consecuente proyecto de modernización económica afectaron a la ciudad de Concepción durante la segunda mitad del siglo XIX, en relación con los mecanismos de control social utilizados por las élites gobernantes. El eje de nuestro estudio se estructura en torno al papel que jugó la policía en la política de disciplinamiento en la ciudad de Concepción. Para este caso hemos tomado en cuenta la propuesta de Michel Foucault, en cuanto considera que la policía es una condición relevante para la existencia de la urbanidad.

El liberalismo, en el período de tiempo contemplado en este trabajo, entendía que para obtener el progreso socioeconómico del país era necesario establecer el orden social. Se hacía prioritario, entonces, convertir a los pobres urbanos de "clases peligrosas" a "clases trabajadoras", para lo cual las políticas educacionales y punitivas se conjugaron en la búsqueda de tales propósitos. El papel jugado por la policía fue crucial en este proceso, ya que posibilitó la instalación de los discursos uniformistas elitarios en los sectores subalternos, quienes mediante la apropiación de los mismos coadyuvaron a la construcción de hegemonías.
\end{abstract}

Palabras clave: hegemonía, control social, Concepción.

\begin{abstract}
This work aims to find out how the adoption of the liberal model of development and the ongoing project of economic modernization, affected the city of Concepción during the second half of the nineteenth century, in relation to the mechanisms of social control used by the governing elites. The core of this study is centered on the role that the police played in the policy of disciplining in Concepción. For this case, we have considered Michel Foucault's theory, that the police is a relevant condition for the existence of urbanity.

Liberalism, within the period of time considered in this work, understood that in order for the country to achieve socioeconomic progress of the country, it was
\end{abstract}

\footnotetext{
Doctor en Historia por la P. Universidad Católica de Chile. Académico de Historia de Chile y Latinoamérica en el Departamento de Ciencias Sociales de la Universidad del Bío-Bío y de Ciencias Históricas y Sociales de la Universidad de Concepción (Chile). Correo electrónico: mrojas@ubiobio.cl

** Este trabajo forma parte del Proyecto Fondecyt N ${ }^{\circ} 1080192$, "Cultivando un "ser moral": modernización y control social en las provincias de Concepción y Ñuble (1850-1900)”, 2008-2010.
} 
necessary to establish social order. It was made a priority then, to convert the urban poor from "dangerous people" to "working-class", because of this educational and punitive policy was combined in the search of such intentions. The role of the police was crucial in this process, as they made the installation of unifying elite discourses in subaltern groups possible. Through the appropriation of these discourses the subalterns themselves helped to contribute towards the building of hegemonies.

Key Words: hegemony, social control, Concepción.

Fecha de recepción: marzo de 2011

Fecha de aceptación: agosto de 2011

"Hay ciudades porque hay policía, y porque hay ciudades tan perfectamente policiadas, surgió la idea de trasladar la policía a la escala general del reino".

Michel Foucault, Seguridad, territorio, población

\section{EL CENTRO Y EL MARGEN: METÁFORA ESPACIAL Y SOCIAL}

Para América hispana, en general, y Chile, en particular, el siglo XIX es un período de rupturas, transformación y establecimiento de nuevos paradigmas. Entre estos últimos podemos contar: la formación de los Estados nacionales, la adopción mayoritaria del sistema republicano de gobierno y la preferencia del liberalismo como proyecto político y modelo de desarrollo, al menos desde la segunda mitad del siglo. La mayoría de estas decisiones fueron tomadas exclusivamente por las élites dirigentes, debido a la exclusión política de la sociedad civil durante gran parte del siglo ${ }^{1}$. El establecimiento de estas y otras ideas pretendía ir configurando un sistema social y político uniforme en la población, a partir de discursos emanados "desde arriba". La estructura jerárquica en la instalación de paradigmas cuyo objetivo era organizar la sociedad en torno a visiones comunes es lo que hemos denominado "discursos uniformistas elitarios".

El Estado chileno, en la segunda parte del siglo XIX, mantiene un modelo conservador en lo político, pero adopta un esquema liberal en lo económico. Hacia 1850, la economía chilena se vio estimulada por la demanda externa, que si bien dio origen a períodos de bonanza transitoria, fueron seguidos por una rápida contracción ${ }^{2}$. A pesar de ello, y vinculándose a modelos adoptados por otros países latinoamericanos, el Estado chileno opta por el modelo liberal de desarrollo, con la certeza de que ello sería fuente de progreso.

1 Cfr.: Simon Collier, Chile. La construcción de una república, 1830-1865, Santiago, Ediciones Universidad Católica de Chile, 2005, 68-75; Gabriel Salazar y Julio Pinto, Historia contemporánea de Chile, Santiago, Lom Ediciones, 1999, I:35-39.

2 Luis Ortega, Chile en ruta al capitalismo, Santiago, DIBAM, 2005, 93; Marcelo Carmagnani, Desarrollo industrial y subdesarrollo económico. El caso chileno (1860-1920), Santiago, DIBAM, 1998, 136-138. 
En este escenario, el consiguiente proyecto modernizador requería de una condición básica: el orden social ${ }^{3}$. Para conseguir este objetivo se recurrió a diversos mecanismos que permitían ejercer un efectivo control de la sociedad, entre los cuales se contaban la organización de la administración de justicia y la creación de cuerpos de policía. A estos organismos, creemos, debe sumarse un tercero: la participación de la prensa como medio de difusión de los discursos homogeneizantes.

Para completar la estructura de poder en la cual se insertan los discursos uniformistas hay que considerar el territorio, pues será en este donde se ejercerá el poder estatal. El territorio está determinado por límites definidos: es un espacio organizado, mensurado y controlado, lo que trae como resultante el fraccionamiento, ya que el poder estatal se ejerce sobre divisiones territoriales menores. En este caso estudiaremos una de esas divisiones, el espacio urbano, en particular, la ciudad de Concepción.

Como es sabido, la oligarquía chilena durante el siglo XIX mantuvo un control político riguroso, además de la posesión del poder económico ${ }^{4}$. Por lo mismo, en pos del proyecto modernizador de tipo liberal que adoptan, las élites dirigentes elaboran políticas de control social, con el fin de organizar el Estado conforme a los requerimientos que dicho proyecto precisaba. Esto no era ajeno a la tradición cultural hispánica. Ya Ángel Rama, nos advierte de este hecho, al señalar que,

"Para llevar adelante el sistema ordenado de la monarquía absoluta, para facilitar la jerarquización y concentración del poder, para cumplir su misión civilizadora, resultó indispensable que las ciudades, que eran el asiento de la delegación de los poderes, dispusieran de un grupo social especializado, al cual encomendar esos cometidos"s.

Recogiendo esta herencia inmaterial del período hispánico, las élites gobernantes intentan imponer nuevos modos de comportamiento de la población, acordes al rumbo que habían decidido para el país. No era tarea sencilla, ya que, como veremos más adelante, algunos patrones de conducta de los amplios sectores subalternos llegaban a entorpecer su consecución. El jugarse por el modelo liberal de desarrollo coincide, posiblemente como consecuencia del mismo, con lo que se ha denominado "concentración de la población" en las ciudades. Entre 1865 y 1875 ,

"La población del país creció a una tasa acumulativa anual de 1,3\% y la población rural lo hizo solo a $0,9 \%$. La población aglomerada creció al 3,1 anual, lo cual indica un éxodo significativo de la población del campo. Algunos contemporáneos lo atribuyeron al desarrollo de obras públicas, pero también tuvo como antecedente las mayores demandas que debió soportar la fuerza de trabajo rural y el comienzo del colapso del minifundio como unidad económica capaz de sostener una economía familiar"'.

Salazar y Pinto, op. cit., I:33.

Armando de Ramón, Historia de Chile, Santiago, Catalonia, 2004, 66-67.

Ángel Rama, La ciudad letrada, Santiago, Tajamar Editores, 2004, 55.

Ortega, op. cit., 132. 
Las transformaciones experimentadas por la población tienen directa relación con los cambios en los modos de vida de la sociedad penquista de la segunda mitad del siglo XIX. Hacia 1907, los datos censales arrojaron un 1,52\% de crecimiento de la población nacional, lo que le permitía figurar -en opinión de los miembros de la Comisión del Censo- "honrosamente entre los países más prósperos de la tierra" que a incremento de población se refiere. A renglón seguido opinan que:

"Este aumento está mui desigualmente repartido en las diversas zonas del país. Los departamentos agrícolas del centro han permanecido con su población casi estacionaria o han experimentado un lijero descenso. Este fenómeno que ya se había notado en otros Censos anteriores, no es peculiar a Chile, i aquí se explica más particularmente con la fuerte inmigración interior que ha poblado, en los últimos años, las provincias australes i la rejión del salitre"s.

La ciudad de Concepción, según los datos del censo mencionado, tuvo un sostenido crecimiento de habitantes en la segunda mitad del XIX, en especial entre 1885 y 1895. En cifras redondas, en aquella década el número se incrementó de unas 25.000 a 50.000 personas. Para 1907, la población urbana de la provincia de Concepción sumaba 111.000 habitantes, en tanto que la rural, $135.000^{9}$. Todo lo dicho da cuenta de un cambio en la fisonomía de la ciudad de Concepción, como también en los modos de relacionarse entre los sujetos sociales que la habitan.

El control urbano presenta al menos dos ejes: el del espacio y el de las personas. En cuanto al segundo, el control social de la población urbana presenta rasgos distintivos respecto del de las áreas rurales. Mientras en el campo los vínculos de dependencia entre los grupos de élites y los subalternos son más férreos y directos, en la ciudad esto se diluye. En este último espacio la población tendió a la concentración, y por lo mismo las relaciones humanas debían ser normadas. En su mayoría los comportamientos fueron regulados formalmente por la legislación, la cual durante el período colonial no solo comprendía la ley escrita. Por ello, el derecho indiano incorporaba a la ley, asimismo, la tradición, las costumbres y la opinión de expertos. En la práctica, dicha situación se pudo apreciar hasta mediados del siglo XIX, luego de lo cual el Estado chileno priorizó la ley escrita, dando paso al período de la codificación. También hubo otros mecanismos sociales regulatorios que asumieron la forma de pactos sociales, muchos de ellos tácitos, pero no menos efectivos.

Paralelo a este conjunto de sistemas normativos, nos parece conveniente enfatizar otro aspecto, que a nuestro juicio es relevante y debe tenerse en cuenta: la ciudad presenta una delimitación entre el espacio privado y el público más clara que el campo. La población campesina, acostumbrada a recorrer terrenos ajenos, en la ciudad adquiere la idea de que transitar espacios públicos es un derecho -o al menos tiene la ilusión de ello-. Dicha cualidad le permite, en cierto modo, apropiarse de estos lugares considerados comunes.

Censo de 1907, Santiago, Comisión Central del Censo, 1908, XVII.

Idem.

Ibid., 52. 
A medida que se desarrolla el proyecto modernizador, estimulado por la presencia del capital extranjero, la minería y la banca, la relevancia de las ciudades se torna mayor ${ }^{10}$. Esto implicó que los mecanismos de control social ejercidos por parte del Estado y las élites que lo rigen debieron actualizarse. Si seguimos la propuesta teórica de Michel Foucault, ya no bastará para el logro de los objetivos sociales el mero castigo al transgresor, sino que será necesario "encauzar" las conductas de los sujetos a través del poder disciplinario ${ }^{11}$. En este orden argumentativo podemos indicar que coexistieron en la ciudad de Concepción al menos dos modos de ejercer el control social: uno ligado a prácticas punitivas de castigo directo al infractor (control jurídico-penal del Estado) y otro que ha sido interpretado como "control social del consenso" 12 . Este último aspecto se vincula con lo que Pierre Bourdieu ha llamado "violencia simbólica", donde los grupos dominantes intentan imponer sus postulados y normas al resto de la sociedad civil mediante diversas agencias, como la escuela, los tribunales y la prensa. El propósito de este diseño de control es transformar no solo los comportamientos sino también los valores de los grupos subordinados, de tal modo de que estos lleguen a considerar de consuno legales y legítimas las normativas emanadas desde el Estado, e ilegítimas las propias.

Durante el siglo XIX, esta doble modalidad del control social fue encarnada progresivamente por la policía. Por una parte, esta mantuvo su rol coercitivo y, por otra, asumió un rol "formativo". En este último papel, la policía obedeció al también doble propósito de introyectar en los sectores subordinados los modelos de conductas emanadas desde las élites dirigentes, a la vez que organizar o erradicar algunas de sus prácticas tradicionales que obstaculizaran el éxito del proyecto de desarrollo liberal.

El que determinadas conductas de la sociedad civil fueran permitidas o no dependía de la visión que tuviesen las élites penquistas del grado de perjuicio que eventualmente pudieran ocasionar dichas prácticas al modelo liberal adoptado ${ }^{13}$. Ello hizo posible que algunos comportamientos fueran regulados y que otros se intentaran erradicar. Un ejemplo de los primeros fueron las chinganas y los juegos de bolas $^{14}$ :

\footnotetext{
10 Véase De Ramón, op. cit., 66-69; Salazar y Pinto, op. cit., I:36-39; Carmagnani, op. cit., 39-43.

11 Michel Foucault, Vigilar y castigar, Buenos Aires, Siglo XXI, 2002, 175.

12 Pedro Oliver Olmo, El concepto de control social en la historia social: estructuración del orden y respuestas al desorden, Historia Social 51, Valencia, 2005, 73-74.

13 Para identificar a miembros y redes de la élite penquista resulta interesante el trabajo de Leonardo Mazzei, La red familiar de los Urrejola de Concepción en el siglo XIX, Santiago, DIBAM, 2004. En cuanto a uno de los valores sociales jurídicamente tutelados como fue el honor, véase Mauricio Rojas G., Las voces de la justicia. Delito y sociedad en Concepción (1820-1875), Santiago, DIBAM, 2008, 205-258.

14 Según la lámina que se encuentra en la obra de Claudio Gay, el "juego de bola" se jugaba en una cancha en forma de cuadrilátero. Consistía en introducir en un pequeño arco unas bolas que eran golpeadas con un bastón. Véase Claudio Gay, Atlas de la historia física y política de Chile, París, Imprenta de E. Thunot, 1854, lámina 34.
} 
"En esta clase de establecimientos que sirven para diversiones de la jente del pueblo, no debe permitirse que se planteen en lugares donde no alcanza la policía [...] Si las guardias no pueden velar en estas cosas públicas, por la insuficiencia del número de policiales [...] mui prudente es entonces que no se conceda permiso para abrir chinganas i canchas de bolas en las partes del poblado, donde la policía no pueda mantener el orden i decencia en las diversiones del pueblo. Sabido es también que estos lugares son frecuentados mui a menudo por ladrones u otra clase de jente que está viciada en el crimen"15.

En general, el afán "moralizador" de las conductas del pueblo bajo estaba destinado a controlar tanto las diversiones públicas como los espacios en los cuales se llevaban a cabo. De esta manera, la presencia policial establecía de forma intangible los territorios de centro y periferia: el centro estaba indicado por la mayor presencia policial y, por el contrario, la periferia se definía por la escasa o nula presencia de la misma. Por supuesto esta distinción espacial es arbitraria y se establece desde el punto de vista de los que ejercen el poder hegemónico. Esta construcción subjetiva del espacio y el poder requería ser plasmada en el campo de lo objetivable, como forma de representación tangible de la hegemonía. Así, el centro se hace inteligible para la población, quedando definido por los edificios principales de los poderes públicos ${ }^{16}$.

La población reconoce en el espacio del centro la presencia de la autoridad estatal. Ello queda demostrado en el siguiente episodio ocurrido a Ventura Castillo, una mujer que había sufrido un intento de violación por parte de un sereno, y de quien su sirvienta narró lo siguiente: "Que en esos momentos entraba para la casa y su patrona le dijo que fuera a pedir auxilio [...] y que cuando volvía a avisar que no había encontrado sereno encontró a la Castillo que venía para la plaza tirando el caballo de Rufino Retamal [su agresor]"17.

La mujer se dirigía en dirección a la plaza ya que pretendía estampar la denuncia en la Comandancia de Serenos que se encontraba en aquel lugar. En el imaginario social, el centro urbano se percibe como un espacio controlado, por ende, tranquilo y seguro, en gran parte gracias a la presencia policial. Ello se desprende de comentarios como los siguientes:

"No mui lejos de nosotros el tiempo en que nuestras ciudades mismas eran presa de los ladrones i bandidos de toda especie [...] ¿Cómo se ha logrado hacer desaparecer de entre nosotros tan perjudicial epidemia? Porque es cierto que hoy en día nadie puede faltar a las leyes de un modo alguno tan descarado sin recibir su condigno castigo. No de otro modo que reglamentando las policías urbanas. Desde que se tuvo tan feliz idea han desaparecido la mayor parte de los malhechores que antes nos infestaban. Esta importante medida unida a la paz y la tranquilidad de que gozamos, estableció la tranquilidad en nuestros pueblos"18.

15 El correo del sur (Concepción), 25 de febrero de 1860, 3.

16 Cabe indicar que hacia 1865, en la plaza de Concepción, se edificaron los Tribunales de Justicia y la Intendencia, bajo la dirección del entonces urbanista y director de obras municipales, Pascual Binimelis. Fernando Campos Harriet, Concepción y su historia, Santiago, Academia Chilena de la Historia, 1971, 54.

17 Archivo Judicial de Concepción, Legajo 66, pieza 6, 1852.

18 El correo del sur, 23 de febrero de 1860, 1. 
"Con gran satisfacción i reconocimiento comunicamos al público el ventajoso estado en que se encuentra el servicio de policía [...] Los ladrones y malhechores son perseguidos sin tregua ni descanso, la tranquilidad i el sosiego principian ahora a hacerse sentir de un modo notable entre nosotros"19.

La imagen de ciudad ordenada y depósito de la civilización no es exclusiva de la segunda mitad del siglo XIX, sino que proviene desde antiguo. El avance civilizador de la República romana -y posteriormente del Imperio-, mediante la fundación de ciudades, y el plano de cuadrícula de las ciudades hispanas, donde se asentaban las principales instituciones y autoridades, son ejemplos que posibilitaron la construcción de matrices culturales que consolidaron la imagen de la ciudad como centro difusor de paradigmas. Era un modelo que se escogió conscientemente para la etapa de desarrollo liberal, ya que calzaba con el esquema "moralizador" que se requería para el funcionamiento del sistema socioeconómico.

El rótulo de ciudad está compuesto de múltiples realidades histórico-sociales diferenciadas ${ }^{20}$. Ello permite que la autoridad política, rectora de los espacios urbanos, genere una estructura dialéctica que establezca la metáfora diferenciadora entre un centro civilizado y una periferia bárbara. Debido a ello, podemos afirmar que la ciudad crea marginalidades, pues se piensa desde un centro geográfico y cultural (plaza, edificios públicos, iglesias) que irradia influencias hacia los márgenes.

La generación de marginalidades producto de la creación de un centro puede ocasionar como uno de sus correlatos la aparición de resistencias. Estas no solo son expresiones coyunturales de malestar de tipo individual o grupal, sino que también pueden manifestar contenidos culturales y estilos de vida que han sido estigmatizados por los sectores dominantes. De esta forma, las resistencias se pueden adoptar como una estrategia para enfrentar la hegemonía de las élites ${ }^{21}$.

La condición de vivir en el margen crea una forma de apropiación territorial por parte de los subalternos, en especial de los más desposeídos. Para ellos, la periferia urbana se convierte en su hábitat, un espacio del cual se posesionan y le confieren significados. Cuando algunos miembros de estos grupos se desplazan a los otros lugares de la ciudad, su presencia puede adquirir el carácter de provocación. Se desafía a la autoridad, las leyes, las costumbres y los valores que se intentan imponer por parte de los grupos hegemónicos, otorgándole a la ciudad el rasgo de espacio conflictivo.

En Concepción, estos espacios de periferia marginal fueron delimitados por la misma autoridad. El decreto para el cobro de los derechos judiciales en la ciudad, promulgado en marzo de 1866, establecía lo siguiente:

19 El correo del sur, 6 de marzo de 1860, 3.

20 José D'Assunçao Barros, Ciudad e Historia, Santiago, Ediciones UCSH, 2008, 50.

21 Peter Burke, Historia y teoría social, México, Instituto Mora, 1997, 104-105. 
“Apruébase el acuerdo celebrado por la Municipalidad de Concepción el 8 de enero último en que se fijan para el cobro de los derechos judiciales los límites urbanos siguientes: al norte, el foso que deslinda la ciudad hasta el fin de la calle de Ongolmo [...]; al sur, el cerro Caracol [...]; al oriente, el estero denominado Agua Negra; i al poniente, el BíoBío hasta la punta de Chepe"22.

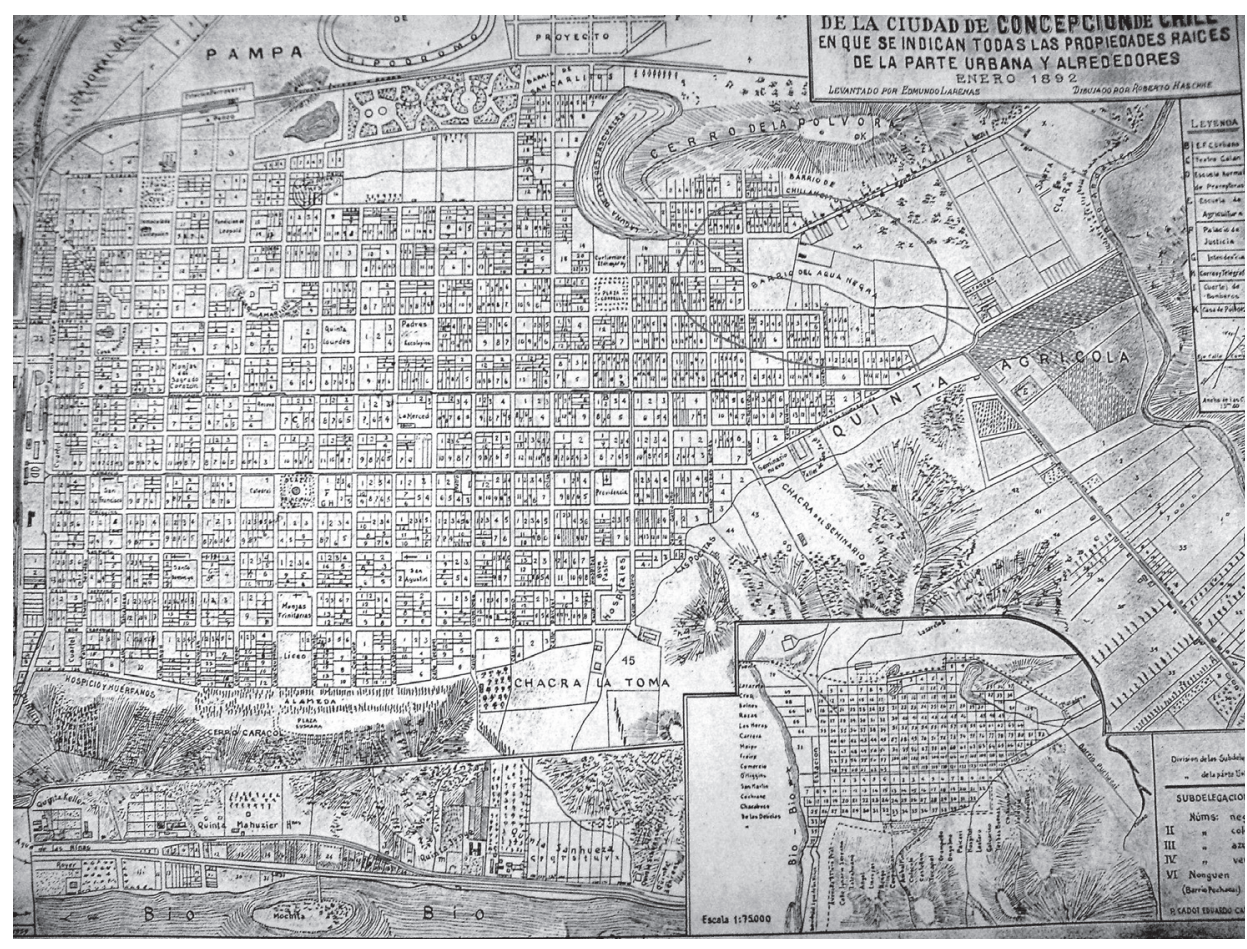

Figura 1. Plano de la ciudad de Concepción levantado por Edmundo Larenas en enero de 1892. Hemos destacado la localización del sector de "Agua Negra", solo para su identificación visual. En el original no está delimitado de esa forma.

Especial atención nos merece el límite oriental de la ciudad, esto es, el sector denominado Agua Negra. Los relatos que nos llegan de ese sitio hablan de un lugar donde la criminalidad era frecuente y el control social ejercido por el Estado, a través de la policía, era casi inexistente. La proliferación de los salteos en aquella zona nos indica la existencia de un espacio conflictivo, donde las víctimas provenían principalmente de otros lugares:

22 Demarcación de Concepción para el cobro de los derechos judiciales, Santiago 12 de marzo de 1866. 
"El domingo en la noche, varios salteadores dieron algunos garrotazos en el 'Agua Negra', a un joven que venía de Puchuncai con dirección a esta ciudad [...] Las patrullas que rondan por los suburbios del pueblo deben fijar su atención en el paso de 'Agua Negra', con preferencia en los demás alrededores, porque los criminales ahí se parapetan las más de las noches para atacar a los viajeros" 23 .

\section{En otra ocasión ocurrió que}

"Uno de los individuos que se ocupa de tocar por las calles el 'organito', cuyo nombre nos ha sido imposible averiguar, el sábado andaba ejerciendo su profesión, a las ocho i media de la noche, cerca del 'Agua Negra'. En el camino encontró cuatro hombres que quisieron gustar de los agradables sonidos de la música i cuando hubo ya terminado la cantidad de piezas que ellos exigían, por vía de llapa, le molieron a palos, golpes que hasta ahora han puesto en peligro la vida de este desgraciado. Los escasos medios que tenía en los bolsillos desaparecieron como es natural i aún se dice que el pobre 'organito' pereció en la batalla, esto es, se lo llevaron consigo" 24 .

Relatos como los descritos dan cuenta de la conflictividad producida por apropiaciones territoriales de parte de sujetos que vivían en espacios de marginalidad. Se instaló en ellos la concepción del ejercicio de una cierta soberanía sobre los espacios periféricos. Nos parece útil, para analizar lo descrito, la propuesta teórica de los $l u$ gares y no lugares del antropólogo francés Marc Augé. Desde esta perspectiva, el espacio del margen -o cualquier espacio que se convierta en "marginal" aunque no esté situado en los límites geográficos-, se constituye para sus habitantes en un lugar y los espacios centrales en no lugares. Para Augé: "Si un lugar puede definirse como lugar de identidad, relacional e histórico, un espacio que no puede definirse ni como espacio de identidad ni como relacional ni como histórico, definirá un no lugar"25.

El sector de "Agua Negra", entonces, se puede entender bajo esta premisa. Es un espacio marginal donde sus habitantes se sienten protegidos, amparados y dominantes. Es un espacio de identidad, un lugar al cual los sujetos pueden recurrir luego de transitar por otros espacios que les resultan ajenos y con los cuales no crían arraigos ni solidaridades, es decir, que para ellos resultan ser no lugares. Al quedar al margen del modelo modernizador de tipo liberal abrazado en Chile durante la segunda mitad del siglo XIX, los malestares incoados por los habitantes de las periferias se expresan en rebeldías, desafiando la legalidad. Un relato ofrecido por la prensa lo expone de la siguiente manera:

"El domingo, a las nueve de la noche, otro transeúnte montado a caballo pasaba por la calle de Freire [...] Sin que el guardia le hubiese ordenado hacer alto, en fin sin causa alguna que incomodara a su señoría, le disparó un tiro de pistola con bala i en seguida dio inmediatamente carrera a su caballo, dirijiéndose hacia el 'Agua Negra'. El sereno descargó también su carabina contra el facineroso, pero sin resultado alguno"26.

El correo del sur, 10 de abril de 1860, 3.

El correo del sur, 15 de mayo de 1860, 3. 24.

Marc Augé, Los no lugares. Espacios del anonimato, Barcelona, Gedisa, 2004, 83.

26 El correo del sur, 15 de mayo de 1860, 3 . 
La conflictividad resultante de la presencia de las distintas culturas legales (esto es, las distintas percepciones que los grupos sociales tenían de la ley), producto de una población urbana espacialmente concentrada, numerosa y heterogénea, fue tal que algunos llegaron a apreciarla como un combate entre dos bandos antagónicos bien diferenciados. Un articulista de mediados de siglo XIX advertía: "decididamente esta jente quiere hacernos la guerra a sangre y fuego" ${ }^{27}$. Frases como esta dan cuenta de los choques, en ocasiones violentos, que llegaban a producirse cuando se relacionaban los habitantes de los márgenes y los del "centro". Si bien esta tensión social no era permanente en cuanto a su visibilidad, sí estaba latente. Ello posibilitó que, por una razón u otra, el conflicto pudiera llegar a hacerse explícito si es que algo gatillaba el descontento o se daba la ocasión para manifestarlo.

Cuando calificamos a los sujetos como habitantes del "margen" o del "centro", nos referimos no solo a aspectos de localización espacial, sino también a contenidos culturales. Los habitantes del "centro" paulatinamente fueron adaptando e incorporado a sus patrones de comportamiento los discursos emanados de las élites dirigentes; situación contraria ocurrió con los residentes del "margen", o bien aquellos que de alguna manera se consideraban marginados. En este segundo sector, el no someterse a los requerimientos del Estado hizo que fuesen vistos como perturbadores del orden social, generando, a los ojos de las autoridades, una situación anómica.

Para poder combatir ese estado de cosas, se esgrimió como solución la participación de la policía: "Es indudable que nuestras policías, como las de todo el mundo, son las que más contribuyen al mantenimiento del orden público, al respeto de la propiedad i a la aprehensión i castigo de los malhechores que infestan a las sociedades" $"$.

En el contexto de la existencia de un Estado guardián, preocupado por reguardar el orden social y, por ende, la propiedad privada, la policía jugaba un papel de primerísima importancia en cuanto garante de la moralidad, el buen encauzamiento de las conductas y la contribución al castigo de los que atentan contra los valores sustentados por los grupos dominantes. A los ojos de estos últimos, las conductas de la población, entregadas al libre arbitrio de los sujetos, generaban corrupción y faltas a la moral, si es que no se ejercía sobre ellas un control policial: "El pueblo se corrompe i desmoraliza en mayor grado cuando la policía no puede vigilar constantemente en los lugares donde se establecen diversiones públicas [...] El único modo de evitar la propagación del crimen es castigar a los delincuentes" 29 .

La existencia de espacios diferenciados, que hemos clasificado de manera amplia en una estructura binaria denominada "centro y periferia", es la resultante de la irregularidad con que el discurso uniformista estatal llegaba al conjunto de la sociedad penquista. La irradiación de las normas, emanadas desde el centro urbano, se difuminaba a medida que el contingente policial - policía de seguridad y urbana- era in-

\footnotetext{
27 El amigo del pueblo (Concepción), 5 de julio de 1858, 3.

28 El correo del sur, 19 de junio de $1860,1$.

29 El correo del sur, 10 de marzo de 1860, 3.
} 
capaz de ejercer control en los márgenes del territorio de la ciudad. Esa era la queja que se hacía sentir hacia $1860^{30}$, la cual fue decreciendo hacia fines de siglo, en gran medida por la efectividad de las labores policiales.

Sin embargo, y aunque el control policial ejercido para "civilizar las costumbres" de la población se percibía exitoso, en la práctica el funcionamiento de las policías estaba lejos de ser ejemplar. Una de las quejas recurrentes en la segunda mitad del siglo XIX fue el abuso policial. En su aspecto formal, el ejercicio del poder requería del uso de la coerción y la sanción para poder ser efectivo, lo que implicaba que los agentes del Estado -en este caso la policía- fueran portadores de tales facultades, las que, sin las cortapisas adecuadas, podían conllevar a situaciones abusivas. Esto ocurrió en la ciudad de Concepción. Como hemos establecido antes, la adopción del modelo de desarrollo liberal requería como condición indispensable el orden social. La primera etapa de la "civilización de las costumbres" de la población (hasta 1860) privilegió la coerción como medio disuasivo, lo que trajo aparejadas evidentes situaciones de maltrato. Da cuenta de ello la amarga queja que hizo el 21 de mayo de 1858 José del Rosario Levancini, vecino de la ciudad, por el "abuso arbitrario de autoridad":

"El domingo 16 del actual [mayo de 1858] como a las nueve y media de la mañana el ajente de policía Diego Zúñiga lo acudía con sendos huascasos a José Mercedes Torres, porque no marchaba lijero al cuartel de policía a pagar la multa que trataba de sacarle por haber galopado, según me dijeron. Viendo la crueldad de Zúñiga con aquel infeliz y movido de la compasión que es tan natural en semejantes caso, le dirijí la palabra a aquel cabirro, diciéndole que no maltratara tan cruelmente a su víctima, que usara de más piedad y que para cumplir su deber no era necesario que fuera tan insolente" ${ }^{31}$.

La respuesta del policía no se hizo esperar, pues estampó una querella acusando a Zúñiga de haberlo llamado "pícaro y ladrón”, ofensas que eran comunes en aquella época y que afectaban directamente la honra de los sujetos. Como consecuencia de lo anterior, José Rosario Levancini vio cómo el decreto número 13 emanado de la Intendencia lo condenaba a una multa de diez pesos, "aplicable al ramo de composición de calles, según acuerdo municipal" 32 , la cual debía pagarse en el plazo máximo de 24 horas. Ante esta situación, el sancionado José Levancini denuncia ya no solo el maltrato policial sino, además, la connivencia de las autoridades, en este caso del intendente de la provincia, frente a tales actuaciones:

30 "Cuando se aumentó la fuerza de nuestra Guardia Municipal, creímos equivocadamente que con cien policiales bastaría para custodiar a la población. Pero después nos hemos desengañado, pues la dotación actual es eternamente insuficiente para que los intereses públicos no estén al alcance de los malhechores i malvados. Demasiado sabido es el abandono que quedan las calles transversales i suburbios de pueblo durante la noche i no podremos decir que esto sea una falta voluntaria del Comandante de policía, sino que no hai más empleados de que disponer, por más economía que se haga del servicio". El Correo del Sur, 21 de abril de 1860, 4.

31 El amigo del pueblo, 21 de mayo de $1858,3$.

32 Ibid., 3. 
"Aún no hacen quince días a que el nuevo Intendente ha tomado posesión del alto puesto a que lo elevaran su elocuencia oratoria y demás servicios que ha prestado a la causa del gobierno $^{33}$, y que en este corto tiempo, cuando todos esperaban que adoptase una marcha franca y conciliadora, es cuando lo vemos desplegar una actitud hostil y parcial, dando un ascenso extraordinario al poder omnímodo de los pacos y vejado con multas al ciudadano honrado y pacífico" 34 .

El hecho descrito no era coyuntural ni esporádico ${ }^{35}$, más bien respondía a una práctica extendida entre las autoridades y sus agentes, en el afán de llegar a controlar los hábitos de la población que se encontraban reñidos con las conductas que pretendían imponer. Esta situación explica las palabras de desánimo y desafío de José Levancini al final de su editorial:

“Ahora juzgue el público acerca de la integridad del nuevo Intendente, y dígase cuál es el artículo del bando de policía que yo haya quebrantado [...] Ya en adelante todos deben saber que no hay facultad para exijir moderación a un señor Paco, u aunque estos estropeen o maten, si les place, a cualquier individuo, nadie tiene derecho para reprobar semejantes excesos.

Pronto estoi para probar la efectividad de los asertos emitidos ante un jurado o ante cualquier autoridad, y bien puede Su Señoría mandarme dar de azotes o embargar mi tienda, si le place, pues a todo esto estoi resuelto, ya que las circunstancias de la nueva política me colocan en este raro y desagradable caso" ${ }^{36}$.

El apoyo del intendente al policía agresor dejaba entrever la existencia de una política gubernamental que requería expresar uniformidad de criterios para no resquebrajar la estructura institucional. Así, la autoridad pretendía evitar el desmoronamiento de la política coercitiva, que creía conducente al orden.

33 Si bien el artículo no identifica al Intendente, según la información que disponemos debería ser don Rafael Sotomayor Baeza, quien ejerció ese cargo entre 1853 y 1859. Cfr.: Fernando Campos Harriet, Historia de Concepción, Santiago, Universidad Técnica del Estado, 1979, 231. Lo extraño es que en el relato de José del Rosario Levancini, este indica que el "nuevo Intendente" había tomado posesión de sus funciones solo hacía 15 días, esto es, el 6 de mayo de 1858.

34 El amigo del pueblo, 21 de mayo de 1858, 3 .

35 Como ejemplo: el 24 de mayo, "un paco en Talcahuano ha causado tres heridas a un extranjero, dejándolo exánime, y en este estado lo condujo arrastrando al pegual de su caballo hasta la cárcel donde lo engrillaron. Al día siguiente viendo su mal estado lo examinó un médico que puso en duda que viviese... Pedir a la autoridad que tome medidas para evitar las repeticiones de hechos semejantes es perder tiempo". El amigo del pueblo, 31 de mayo de 1858, 4. "Hoy en la mañana, conducía un policial al cuartel a un pobre hombre ébrio, a fuerza de látigo, como si fuera una bestia". El amigo del pueblo, 13 de septiembre de 1858. "Se nos informa que noches pasadas fueron conducidos al cuartel de policía cuatro individuos que acababan de salir del club Baquenadista i que tranquilos se dirijian a sus casas por la calle del Comercio... se nos asegura que el tal oficial de policía hizo conducir a los reos a las pesebreras i los obligó a barrer i asear aquellos lugares, i en seguida aceptó la multa que en la noche no quiso aceptar, por estar mui cargado de sueño". La libertad católica (Concepción), 10 de agosto de 1881.

36 El amigo del pueblo, 21 de mayo de 1858,3. 
Durante toda la segunda mitad del siglo XIX, la queja social relativa a los abusos policiales se hizo sentir, en especial en los sectores más desposeídos. "Siempre hemos de ver arbitrariedades, abusos sobre abusos" 37 , reclamaba un penquista; "le suplico me flanqueen algún lugar en su periódico para vindicar mi honor públicamente vulnerado por uno de esos actos de abusos de autoridad que los artesanos parecemos condenados a sufrir desde las últimas elecciones" ${ }^{38}$, se quejaba Severino Rodríguez. Frases como las descritas se repitieron constantemente durante el período indicado. El periódico $\mathrm{La}$ Igualdad, en un crudo editorial titulado "Situación Vergonzosa", ponía de manifiesto que la política represiva del control social, llevada a cabo por el Estado a través de la policía de seguridad, no había desaparecido en la provincia del Concepción finisecular. Un episodio que sustenta lo dicho ocurrió en la ciudad de Tomé:

“A la cárcel! He ahí la voz y la razón del gobernador, ejecutada con humillación cerval por el verdugo del pueblo, el comandante de policía; a la cárcel! Es la voz de mando, el resorte político con que pretenden conculcar los lejítimos derechos de honrados ciudadanos, el ariete con que pretenden romper las filas unidas de los hombres de trabajo [...] El progreso se impone por sí, mal que pese a mandones sinvergüenzas y atrabiliarios, y las cadenas no son si no un estímulo más para la unión de la clase que la casta aristocrática se empeña en llamar vil y despreciable" 39 .

Esta estrategia de control social, vía coerción estatal, se verá complementada en la segunda mitad del siglo XIX por otra: la coerción social por el consenso. A nuestro entender, esta segunda fórmula fue aún más efectiva en la instalación de las normas provenientes de las élites dirigentes, iniciando una segunda etapa en el proceso de "moralización" de los sectores subalternos. En las páginas siguientes analizaremos esta situación.

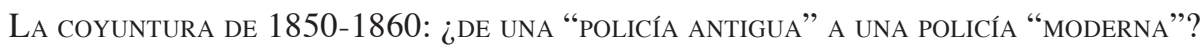

Al historiar el control social ejercido por la policía en la ciudad de Concepción, nos hemos encontrado con la existencia de dos etapas claramente diferenciadas. Si bien no es posible indicar una fecha precisa para datar la transformación en las prácticas de las funciones policiales, sí se reconoce un lapso, entre 1850 y 1860 , durante el cual se produce la coyuntura histórica que delimitaría estos dos momentos.

La primera etapa a la cual nos referimos iría desde de los inicios de la organización republicana hasta alrededor de 1860. Durante este período, la policía se caracterizó por asumir un rol predominantemente coercitivo. Para encontrar una pista que nos permita comprender las razones de la política represiva utilizada por las autoridades estatales hasta mediados de siglo, resulta útil leer al entonces intendente de la provincia de Nuble, Ignacio García. Dicha autoridad, en un informe dirigido

\footnotetext{
37 El amigo del pueblo, 12 de julio de 1858,3 .

38 El amigo del pueblo, 26 de julio de 1858, 3.

39 La igualdad (Concepción), 10 de junio de 1893, 1.
} 
al ministro del Interior, describía la mala organización de la Guardia Nacional que estaba a su cargo, la cual tenía la imperiosa tarea de imponer el orden. El logro de tal función no se habría visto entorpecido por las carencias presentadas por la policía, gracias a ciertos rasgos culturales de la población, que hicieron posible implementar las medidas coercitivas. Ignacio García consideraba que la "ignorancia, buena fe i los hábitos de subordinación que reinan en nuestras masas" ${ }^{40}$, fueron factores favorables para ejercer un control efectivo de la población.

De esta forma, y debido a que los miembros de la Guardia Nacional también eran de extracción popular, este rasgo cultural de la comunidad habría ayudado al control mismo de los cuadros policiales, lo que, en opinión del intendente de Nuble, habría sido un factor morigerador de las tropelías que podrían haberse cometido en mayor número. Para él, ello habría permitido ahorrar, "Felizmente hasta ahora el palpar los horrendos atentados que eran de esperarse de tan mala organización. Este espíritu de orden i dependencia hacia los jefes que predominan en nuestra Guardia Nacional, se hace sentir mui particularmente en esta provincia" ${ }^{41}$.

El análisis del intendente de Nuble no nos parece inadecuado, ya que el éxito del ordenamiento social habría pasado por lo que él consideraba un rasgo característico de las "masas": los hábitos de subordinación. Lo que no compartimos de la opinión del intendente Ignacio García y de historiadores como Alberto Edwards ${ }^{42}$ es la idea de una obediencia sin conciencia, más precisamente conciencia política. Dicho de otro modo, nos parece que la subordinación de los sectores subalternos respondería a la existencia de criterios legitimadores que informarían sus prácticas, los que habrían posibilitado la creación de hegemonías por parte de las élites gobernantes. No fue una obediencia a ciegas, sino que se insertó dentro de una idea de cómo debía estructurarse la sociedad y los roles asumidos por los distintos grupos que la componían. Con el correr de la segunda mitad del siglo XIX, la "economía moral" de la población se va transformando, y con ello sus exigencias y demandas sociales. Ya se deja entrever este cambio hacia 1858, cuando la acostumbrada práctica policial de llevar a la fuerza a los ebrios al cuartel fue cuestionada en los siguientes términos:

"Hoi en la mañana, conducía un policial al cuartel a un pobre hombre ebrio, a fuerza de látigo, como si fuera una bestia. Esta manera de tratar a un hombre que no está en su juicio, es enteramente bárbara; y el comandante debe prohibirlo con penas para cortar esos abusos, y hacerles entender que ellos no son para castigar y maltratar a los que conducen presos" $"$.

$40 \quad$ Memoria que el Intendente de Nuble dirije al Sr. Ministro del Interior. Chillán, 16 de abril de 1850. Reproducida en El Araucano (Santiago), 14 de mayo de 1850.

${ }^{41}$ Idem.

42 Es conocida la opinión de Alberto Edwards al respecto, quien afirmó: "En realidad, como elementos políticos capaces de cierta acción, solo existían en Chile la sociedad aristocrática de Santiago y el Ejército, cuyos jefes más experimentados y aguerridos estaban vinculados a Concepción. El resto del país era materia inerte, ganado humano. Habían de transcurrir cien años antes de que la plebe adquiriese alguna noción de los derechos políticos que le reconocía el régimen legal”. Alberto Edwards, La Fronda Aristocrática, Santiago, Editorial del Pacífico, 1976, 24.

43 El amigo del pueblo, 13 de septiembre de 1858, 3 . 
Como se advierte, se consideraban intolerables ciertas actuaciones policiales catalogadas de abusivas. Este calificativo responde a nociones de lo que la población estimaba adecuado o no en el comportamiento de los distintos actores sociales, por lo que estructura una visión política. No se observa en ello, necesariamente, una crítica al sistema punitivo estatal ejercido por la policía, sino más bien el reclamo se dirige contra lo que califican como abusos o excesos de la misma. No obstante, aunque siguió habiendo abusos de la policía en la última parte del siglo, las quejas por ellos fueron menguando en número y modificándose en cuanto a sus razones. Estas últimas se centraron en el respeto a la dignidad de los sujetos, como fue el caso de las detenciones por sospecha: "Pedimos a la policía se fije un poco más en las personas que hace tomar por sospechosas, pues así se evitará el que sean arrastradas a la cárcel personas honradas i de buena conducta" ${ }^{4}$.

A partir de 1851 hubo un aumento en la dotación policial, hecho que está en sintonía con el concepto de control social como garante del orden social. Esta situación tuvo detractores, quienes, entre las críticas enunciadas, esbozaban desconfianza en que ello colaborase con la disminución del delito, más bien consideraban que el incremento de policías respondía a otros objetivos. En el sentido de lo expresado, hacia fines de la década de 1850 se escribió el siguiente comentario:

\begin{abstract}
"Desde el año 51 la población de Concepción a lo sumo habrá aumentado en dos mil personas. En aquella época el cuerpo de serenos se componía de un comandante, cuatro cabos y veintidós serenos. El comandante gozaba 600 ps. de sueldo, y daba fianza por tres mil pesos para responder por los robos que se hiciesen en la población durante la noche. ¿Por qué son necesarios hoy ciento diez y nueve individuos para cuidar la población? ¿Se destinará tal vez una parte a servir de domésticos a las autoridades para que no se diga que solo el Intendente tiene esa regalía? Aún así, su número es exorbitante. ¿Se buscan quizá ciento diez y nueve votos para oponerlos a los votos ciudadanos? [...] Para evitar los robos no es el número de pacos lo que más vale, como lo prueba lo ocurrido desde que se duplicó el número, quitando la fianza que rendía el jefe. Vuelva a ponerse en vigor esa garantía del vecindario, y serán raros los casos de robos. Pero no, no es el bien de la población lo que se busca, son votos seguros" $"$.
\end{abstract}

En la cita reseñada se percibe el escepticismo del articulista. Su argumento gira en torno a dos ejes: el primero indica que la lucha eficaz contra los robos no tenía conexión directa con la existencia de más policías. Al contrario, en su opinión, la práctica demostraría que los robos no habían disminuido a pesar de que había aumentado al doble el contingente policial. El segundo argumento deja entrever una suerte de manipulación electoral del contingente policíaco, además del uso personal (especie de servidumbre) que algunas autoridades hacía de él para fines ajenos a dar seguridad a la población. Para quien escribe el editorial, habría sido más eficaz continuar con el sistema de "fianza" que debía colocar el comandante de Serenos como resguardo para la población en caso de robos. Hacia mediados de siglo, el monto de este depó-

44 La libertad católica, 9 de septiembre de 1882, 3.

45 El amigo del pueblo, 20 de agosto de 1858,3. 
sito correspondía a cinco meses de sueldo del mencionado oficial. Esta fianza tenía el propósito de resarcir, inferimos que a las víctimas de robos nocturnos, el monto que les había sido sustraído. Era una especie de multa/seguro que cumplía una doble función: por una parte, presionaba al comandante de Serenos a ejercer su tarea con mayor prolijidad, por otra, ayudaba a la víctima del robo a paliar las pérdidas sufridas.

El trasfondo de lo mencionado contenía en sí un tipo de discurso oculto, a saber, el anhelo de mantener una estructura policial antigua, previa a 1851. En un artículo anterior, del 13 de agosto de 1858, se describían con mayor detalle las bondades del antiguo sistema, del cual se decía:

"Con lijeras modificaciones, la organización que tenían antes los cuerpos de policía sería la más adecuada para el objeto a que está destinada esta institución. Prueba de ello es que con un personal mucho menos numeroso, la sesta o la séptima parte del que tenemos ahora, la policía estaba mejor servida, había más seguridad, no tenían lugar los atentados cometidos por los mismos individuos de los cuerpos de policía de que se quejan en todas partes, la policía era más respetada y no encontraba de parte de la población ese sentimiento de antipatía que ha sido producido por la mala conducta de algunos individuos" ${ }^{\prime 4}$.

Entre las cualidades de la "policía antigua" que merecían el elogio del articulista, se encontraban:

"Antes la policía estaba servida por dos cuerpos, el de vigilantes y el de serenos, los primeros para el servicio de día y los segundos para el de noche. No deja de haber fundamentos para esa división: el servicio de la noche es más delicado y más penoso, exije hombres más abonados [...] Estos cuerpos tenían hasta cierto punto una existencia independiente el uno del otro. En el de serenos que era el cargo más delicado, se exijía para la incorporación algunas condiciones, como la presentación de una recomendación de una persona conocida [...] El comandante del cuerpo, el mayor, los capitanes, los sarjentos, debían rendir una fianza para responder por los robos que se cometían en la ciudad con ciertas condiciones" ${ }^{\prime 4}$.

Esta estructura policial habría sido bien recibida por la población, que consideraba especialmente a los serenos como sujetos merecedores de respeto y consideración. Al mismo tiempo que se destaca el papel de estos funcionarios, se desliza una crítica hacia la actuación de los vigilantes, quienes tendrían mucha semejanza con la "nueva policía". De ahí el siguiente comentario: "Debido a todo esto era que los serenos no encontraban esa antipatía, que persigue en el día a los individuos de la policía y que aún entonces perseguía a los vigilantes, cuerpo que en algo se asemejaba a los cuerpos de policía actuales" 48 .

Los comentarios entregados por este contemporáneo a los hechos evidenciaban una transformación de las instituciones policiales. El artículo al cual hemos hecho

\footnotetext{
$46 \quad$ El amigo del pueblo, 13 de agosto de 1858.

47 Idem.

48 Idem.
} 
referencia fue escrito en 1858, momento en el cual el autor ya consideraba como negativas las transformaciones sufridas por la policía, en particular los aspectos vinculados con el trato hacia la comunidad. Responsabilizaba de la mala relación entre policía y población al comportamiento de la dotación policial:

"Porque la policía entre nosotros se hace odiosa por su personal, que inspira de por si pocos sentimientos de respeto, por la insolencia y aun crueldad con que ejecuta su comisión y que las autoridades toleran y aun fomentan, creyendo que esa rivalidad, esa antipatía entre el jendarme y el pueblo es una garantía de seguridad. Que la policía se componga de sujetos como los que debían formarla y cesará esa guerra, y la policía encontrará entonces en el mismo pueblo disposición a auxiliarla en su benéfica misión"49.

La extensa descripción que hemos hecho de este artículo responde a que constituye un certero diagnóstico del cambio que sufrió tanto la constitución como la práctica policial entre 1851 y 1860 . Después de 1851, se produjo una entronización de los métodos utilizados por la policía de seguridad diurna. En tanto, las bondades de la guardia nocturna (los serenos), a saber, personal calificado y el respeto de que gozaba por parte de la comunidad, se fueron perdiendo. Hubo una sustitución de estilos policiales, que respondió a un énfasis en la labor coercitiva de la policía. La implementación de este nuevo esquema requería dos aspectos: un incremento en las fuerzas policiales y un distanciamiento entre la policía y la población que debían controlar. Este énfasis se mantendrá, sin mayores modificaciones, hasta comienzos del siglo XX.

Sin embargo, cabe consignar que en 1860 se incorpora otro rasgo de la policía que viene a complementar lo expresado en los párrafos precedentes, inaugurando definitivamente un segundo período del control social en Concepción, caracterizado por el consenso que se logró entre los comportamientos que intentaban inculcar las élites y lo que estuvo dispuesta a asimilar la sociedad civil.

Esta segunda etapa comenzó el 2 de enero de 1860 con la creación de la policía urbana de Concepción. Su gestación contemplaba el abocarse a labores que no estaban cubiertas por las policías de seguridad anteriores, pues debía regular el "aseo, ornato i salubridad de la ciudad" 50 . En este período, la acción policíaca no solo se consolidó como instrumento de control social sino que, además, su accionar fue más efectivo en cuanto a la modificación de las conductas de la población. Ello fue producto de un proceso de décadas donde coexistieron dos estrategias definidas de control social, ya que, al control jurídico-penal del Estado, donde la policía presentaba el rasgo coercitivo, se sumó, como complemento, el control social por el consenso, adscrito a la policía urbana.

Se evidencia, entonces, una yuxtaposición de funciones de la policía: sin abandonar la política "del palo", se incorporó ahora una función de "pedagogía social". Desde 1860 en adelante, los editoriales de los periódicos y los reclamos sociales evidenciados en las opiniones vertidas por partidarios de los sectores subalternos daban

49 Idem.

50 Ordenanza municipal de Concepción, Santiago, 2 de enero de 1860, en: Boletín de las leyes y decretos del Gobierno: 1860, Libro XXVIII. 
cuenta de que la población fue adoptando los patrones de comportamiento esperados por la autoridad con la instalación de un cuerpo de policía urbana. Ya al comienzo de la década del sesenta comenzaron a surgir distintas voces que diagnosticaban las causas del retraso y la marginalidad en que vivían las clases desposeídas. Se concordaba en un punto: había que "regenerar" la población. Este concepto, que había sido utilizado profusamente desde el período de la Independencia, implicaba la idea un "volver a nacer" de la comunidad y daba a entender un anhelo refundacional, en algunos casos sustentado sobre las bases sociales anteriores o bien creando otras nuevas ${ }^{51}$.

En la dirección de lo pretendido por las autoridades y la élite, tanto nacionales como penquistas, el tema de la salubridad se levanta como un aspecto a considerar con urgencia, al mismo tiempo que comenzaba a vincularse con la "educación de las costumbres", máxime cuando las enfermedades que asolaron a la población de la provincia en la segunda mitad del XIX se convirtieron en epidemias. Las opiniones que se esgrimieron para explicar esta rápida difusión de las enfermedades concordaban en la necesidad de modificar las precarias condiciones en que vivía la amplia masa de la población, a las cuales responsabilizaban de los problemas sanitarios. Pero el diagnóstico no quedaba solo ahí, pues los planteamientos higienistas se entrelazaban con las medidas de control social, en cuanto visualizaban como una de las razones de las deplorables formas de existencia de la comunidad a los "malos hábitos" de esta. Es así como, posiblemente con propósitos distintos, quienes abogaban por el mejoramiento de la calidad de vida de los sectores desmedrados llegaban a un punto en común con las autoridades, esto es, la necesidad de transformar las condiciones de vida de la población, tal como queda expresado en el siguiente comentario:

\begin{abstract}
"Mientras tanto, vamos a apuntar un hecho, que pone de manifiesto, a qué pendiente tan resbaladiza nos conducen los malos hábitos i preocupaciones de nuestra clase proletaria. Desde el 29 de enero hasta el 14 de febrero del presente año [1860], han perecido ocho párvulos; i todos pertenecían a la clase proletaria. Esto prueba que la mortandad es espantosa en esta clase de nuestra población, i las causas que las motivan son bien patentes.

El poco cuidado de las madres, la viciada organización de los padres, el jénero de vida a que se someten i el poco cuidado que se tiene con los infantes, son las causas principales de tan horrible mortandad [...] Queremos que se introduzca en el pueblo los hábitos del trabajo, de economía i aseo, que elevando el carácter del hombre, lo hagan mejorar de condición i ser más útil a la sociedad a que pertenecen" ${ }^{52}$.
\end{abstract}

La situación sanitaria se vio agravada con una terrible peste de viruela a comienzos de la década de $1880^{53}$. Esta peste afectó particularmente a los sectores más

51 Cfr: Paulina Peralta, ;Chile tiene fiesta! El origen del 18 de septiembre (1810-1837), Santiago, Lom Ediciones, 2007, 52-53.

52 El correo del sur, 9 de febrero de 1860, 2.

53 Una editorial se refería al respecto de la siguiente manera: "La viruela ha llegado a ser en Chile, especialmente en el Sur, un mal endémico. Nunca se estingue por completo i aunque se cierren los Lazaretos, no deja de haber lo que los médicos llaman casos esporádicos, o aislados en leguaje común, pero que prueban que el jermen del mal existe en estado latente". La libertad Católica, 21 de enero de 1882, 2. 
desposeídos de la ciudad, de hecho se subrayaba el que: "Jamás se borrará del triste álbum de nuestras desgracias locales el recuerdo de la epidemia de viruela de 1880 . En pocos meses vimos desaparecer como la tercera parte de la población indijente de Concepción víctima de la peste" 54 .

En ese tiempo, en los discursos en torno a la enfermedad se verificó un cambio de énfasis en la identificación de la génesis del problema. De los “malos hábitos” en las prácticas higiénicas de la población denunciados en décadas anteriores, se traslada el foco de controversia a la estructura y conformación de la ciudad de Concepción en sí. Se critican las malas condiciones de salubridad del emplazamiento urbano, especialmente el que las medidas higiénicas existentes en la ciudad hayan poseído un carácter discriminatorio conforme a la clase social. La deficiente distribución de agua potable se apreció no solo como un factor de agudización de los problemas de salud, sino también como una manifestación de la desigualdad social existente. Ello sumado a ciertas características climáticas de la zona, por ejemplo el viento, colocaban en el tapete los problemas de localización de los habitantes por estatus social. Esto se evidencia en el siguiente comentario:

"Pues bien, se notó con claridad que el tremendo flajelo [viruela] atacó de preferencia a las habitaciones situadas en el Cerro Amarillo i la Pampa, barrios los más cercanos al Lazareto i hacia los cuales se dirijen precisamente los miasmas pestíferos, arrastrados por el viento [...] Esta sola consideración, fuera de que la población va creciendo sensiblemente por ese lado [noroeste de la ciudad] debe aconsejar la necesidad de trasladar con presteza a otro punto el mal situado Lazareto" 55 .

La región noroeste de la ciudad de Concepción era donde se aglutinaba la mayor cantidad de población con escasos recursos. Como ya dijimos antes, era un espacio conflictivo, pues no solo se encontraba ahí el límite urbano de la ciudad, sino que también el barrio del "Agua Negra" era un espacio donde se manifestaba la rebeldía contra la autoridad estatal y policial. Sin embargo, en la década de 1880 los discursos higienistas provenientes de las élites tuvieron eco en los habitantes de esos espacios límites, que estimaban como discriminadora socialmente la posibilidad de acceder a tal recurso. Vemos en ello una incorporación de los pobres al proyecto modernizador estatal, que implicaba la ampliación de las prácticas higiénicas de las élites al resto de la población. Y este "resto de la población" adoptó finalmente estas prácticas como propias, pues le confirieron legitimidad a los discursos hegemónicos. Hacia 1881, se esgrimía como una de las "necesidades locales" de Concepción el acceso al agua, en el contexto de una desigualdad de clase:

$54 \quad$ La libertad católica, 12 de noviembre de 1881. Según el censo de 1885, la población de la ciudad de Concepción ascendía a 40.302 habitantes. Por lo que si confiamos moderadamente en la información dada por el articulista, los muertos habrían sido, a lo menos un par de miles de personas. Cfr. Memoria presentada al Supremo Gobierno por la Comisión Central del Censo. Censo General de La República, 1907, Santiago, Universo, 1908.

55 Idem. 
"Sin agua no hai aseo, sin aseo no existe salud: de donde resulta que una ciudad sin agua no podrá jamás tener condiciones hijiénicas. Tal vez esta sola circunstancia basta para esplicar el formidable desarrollo que en otros años han tomado en esta ciudad el tifus, la viruela i la difteria o membrana [...] El uso de los baños, tan favorable al aseo i bienestar, está reservado en Concepción para los ricos [...] Tenemos, es cierto, en la Plaza principal una hermosa pila a cuyo alrededor se reúne la gente elegante, pero su caudal de agua es tan diminuto que en caso de un grande incendio serviría de poco eficaz ausilio" ${ }^{56}$.

La alusión a la centralidad de la fuente de agua, en torno a la cual se reunía la gente elegante, nos inserta en la problemática de la "cuestión social", a la que contemporáneos como Augusto Orrego Luco, en su ya clásico ensayo acerca de "La cuestión social en Chile", le prestaban especial atención. El análisis de Orrego Luco giraba en términos afines a los reseñados por el articulista, esto es: la extrapolación de las medidas higiénicas del centro acomodado a la periferia pobre, tanto por fines humanitarios como para evitar conflictos sociales futuros. La fórmula propuesta implicaba la incorporación de los sujetos subalternos al proyecto modernizador. Augusto Orrego Luco fue muy directo y claro en sustentar lo expuesto:

\begin{abstract}
"Así, de una manera muy visible se han formado esas clases altas que nadan en la opulencia y esas clases bajas que se ahogan en la miseria, dueñas las unas del poder y desarrollándose las otras en una atmósfera servil que necesariamente enerva su carácter [...] estamos envueltos en una cuestión social amenazadora y peligrosa, que reclama la más seria atención del estadista [...] si el proletariado se desarrolla nos sumergirá en una de esas situaciones inciertas y llenas de inquietudes que imposibilitan el movimiento comercial $[\ldots]^{\prime 57}$.
\end{abstract}

La receta esgrimida por parte de estos integrantes de los sectores acomodados como solución a los problemas higiénicos y de salud tuvo eco en los sectores populares. Estos últimos habían internalizado progresivamente las medidas sanitarias y de convivencia social propiciadas por el Estado y la élites. Tanto así que las críticas subalternas manifestaron implícitamente una aceptación del proyecto modernizador estatal, subrayando como foco de controversia el que este no hubiese llegado aún a toda la población. Se insistía denodadamente en que esta situación fuera remediada con celeridad, y por lo mismo no es extraño encontrar solicitudes hechas a la prensa en el siguiente tenor:

"Varios vecinos de diversos barrios de la población nos han pedido más de una vez que hagamos presente al señor comandante de Policía, o a quien corresponda, la necesidad de un número suficiente de carretones para extraer con prontitud las basuras que se colocan en cajones en las puertas de las casas en dos días cada semana [...] ¿Qué se obtiene con tomar medidas contra la viruela si por otro lado se la estimula sin querer?" ${ }^{58}$.

56 La libertad católica, 26 de octubre de 1881, 2.

57 Augusto Orrego Luco, "La Cuestión Social", en Hernán Godoy Urzúa, Estructura social de Chile, Santiago, Editorial Universitaria, 1971, 227-228.

58 La libertad Católica, 23 de noviembre de 1881, 2. 
Los reclamos de la comunidad exigiendo una mayor intromisión de la policía en los asuntos cotidianos no solo se circunscribían a los aspectos relativos de salubridad pública, sino que también se hacían sentir cuando se trataba de asuntos que afectaban la convivencia:

\begin{abstract}
"Hai con mucha frecuencia en una casa que existe en la Calle del Comercio, al comenzar la cuarta cuadra de la plaza al río Andalién, acera izquierda. La jentes que las habitan no son nada edificantes i los desórdenes no solo se perciben desde la calle sino que ni aún puede transitarse por allí sin ser incomodado. Varias personas nos piden que llamemos la atención del Sr. Intendente i del Comandante de Policía. Concepción se ha distinguido siempre por su moralidad pública i no conviene que se presenten a la juventud espectáculos como los que se ven en la antedicha casa" ${ }^{59}$.
\end{abstract}

Si bien las críticas a la policía arreciaron, en especial por el comportamiento de sus funcionarios, ello no fue obstáculo para que se pudiese implementar el control social sobre la población. No en vano, hacia fines de siglo XIX, los informes de los intendentes se redactaban en similar contenido al siguiente: "Policía de seguridad: En todos los departamentos de la provincia permanece en el mismo estado, en cuanto a su personal i disciplina, i aún cuando es deficiente, me es satisfactorio manifestar a US., que mediante su auxilio han disminuido notablemente los atentados en los campos i poblaciones" 60 .

En reconocimiento a los logros obtenidos en el control social por parte de las policías urbana y de seguridad de la ciudad de Concepción, la Sociedad Nacional de Agricultura propuso, en 1878, un proyecto de ley que creaba una policía rural, el cual se convirtió en ley en el mes diciembre de $1881^{61}$. Ello da cuenta de que, aun cuando no todo era tranquilidad y seguridad en la mencionada ciudad, el orden social parecía haberse logrado. Incluso ciertos sectores de la comunidad llegaron a solicitar algo impensado treinta años antes: "Pedimos a la policía se fije un poco más en las personas que hace tomar por sospechosas, pues así se evitará el que sean arrastradas a la cárcel personas honradas i de buena conducta" ${ }^{2}$.

La detención por sospecha, a la que hace referencia la cita anterior, era otra manifestación de la desigualdad en la aplicación de la ley, ya que contenía de manera implícita la consideración de que las clases subalternas eran las principales portadoras de conductas delictivas. Ello demuestra que el estilo de vida del "pueblo bajo" se distanciaba de los patrones conductuales que las élites querían imponer -en especial después de 1860-, lo cual los convertía no solo en obstructores del desarrollo económico, sino también en sujetos peligrosos, potencialmente criminales. Baste leer la siguiente cita de un editorial escrito hacia 1860, para apreciar cómo ciertos grupos concebían a los sujetos populares y la validación que hacían de la detención por sospecha: "Los malhechores se concentran en el pueblo i por esto mismo hemos adverti-

59 La libertad Católica, 4 de enero de 1882, 4.

60 Memoria del Intendente de Concepción, Concepción, 28 de abril de 1873.

61 Boletín de la Sociedad Nacional de Agricultura, Santiago, junio de 1888, 616.

62 La libertad Católica, 9 de septiembre de 1882, 3. 
do a la policía que se conduzca al cuartel a todos los vagos e individuos sospechosos que se hallen sin ninguna ocupación; porque la ociosidad, como se dice vulgarmente, es madre de todos los crímenes y vicios" ${ }^{\prime 3}$.

El contraste entre esta última cita (de 1860) y la anterior (de 1882), que llamaba a la policía a ser cuidadosa en la aplicación de este procedimiento de detención ${ }^{64}$, es un reflejo de la transformación que se evidencia en un lapso de veinte años en las prácticas de los sujetos subalternos, además de la nueva percepción que se tenía de estos por parte de integrantes de sectores más acomodados. El que se haya solicitado a los efectivos policiales ser cuidadosos en la detención por sospecha para evitar llevar a la cárcel a "personas honradas i de buena conducta" es manifestación del proceso de apropiación de comportamientos ocurrido en la población subalterna, que las élites consideraban necesarios para la convivencia social. De esta manera, solo quedaron penalizadas prácticas que aún no estaban del todo controladas, tales como: molestar en estado de ebriedad a las personas que transitaban por las calles, usar disfraces públicamente, cargar armas blancas o de fuego sin permiso de la autoridad local, andar a caballo por las veredas, galopar por las calles y no ejercer un cuidado responsable de animales domésticos (perros vagos, caballos, vacunos y otros) ${ }^{65}$.

\section{CONCLusiones}

Al comienzo de este trabajo indicamos que el propósito del mismo era conocer cómo la adopción de la estrategia liberal de desarrollo, por parte de la élite dirigente, afectó los mecanismos de control social ocurridos en la ciudad de Concepción en la segunda mitad del siglo XIX. Para ello identificamos como objeto de estudio a la policía, a quien sindicamos como un actor principal en las transformaciones de las prácticas subalternas de ese período.

La construcción del Estado-nación chileno significó para la élite dirigente la necesaria elección de una estrategia de desarrollo. A partir de 1860 fue definida para estos efectos la estrategia liberal, que significaba un reordenamiento no solo en lo político y económico sino también en lo social. Las implicancias de esta decisión precisaban la conversión de aquellas prácticas de la población subalterna que pudiesen obstaculizar, a juicio de los grupos dominantes, el orden y progreso estatal.

La reestructuración del aparato policial formó parte de los mecanismos utilizados por las élites dirigentes para lograr la anhelada "moralización" de las clases subalternas. De esta manera, el antiguo Cuerpo de Serenos dio paso a la "policía de seguridad", que se instaló no sin tensiones, pues como su labor era en esencia coercitiva, la comunidad la percibió como abusiva e incluso corrupta.

63 El correo del sur, 26 de enero de 1860, 3.

64 La libertad católica, 9 de septiembre de 1882, 3.

65 Ordenanza de policía para la ciudad de Concepción. Santiago, 10 de agosto de 1885, En: Boletín de las Leyes y Decretos del Gobierno; 1885, Libro LIV, $\mathrm{N}^{\circ} 7$. 
La otra cara del control social, esto es, la persuasión y el consenso, estuvo a cargo de otro integrante del cuerpo de policía: la policía urbana. Desde su creación, a inicios de 1860, esta rama policial tuvo por funciones el ornato, aseo y salubridad de la población, con el afán de transformar de manera directa los comportamientos sociales de una población cuya extracción era predominantemente rural. El rol "civilizador de las costumbres" fue, por tanto, una labor cotidiana de persuasión a cargo de esta policía, que si bien contaba con un contingente reducido, ya hacia la década de 1880 fue vista como un ejemplo a seguir en las áreas rurales de la provincia de Concepción.

La vida urbana significó para los sectores populares un proceso de apropiación de lo que las élites identificaban como hábitos de "civilidad". La organización de las construcciones (casas, negocios), la regulación de los comportamientos en espacios comunes y privados, sumadas a la implementación de medidas higiénicas adoptadas en pos de la salubridad pública, son muestras de un nuevo estilo de vida en común que no solo tuvo un reconocimiento legal sino también gozó de legitimidad por parte de la población.

Los nuevos modos de comportamiento social fueron definidos a partir de un centro, que para el caso de Concepción no era solo simbólico (poder estatal y elitario), sino también real. Este último aspecto se objetiva en la diferenciación de los espacios geográficos, donde el centro estaba determinado por la plaza de armas, rodeada de edificios desde donde emanaban las directrices morales (Catedral) y legales (edificios públicos, cuartel de policía). El centro construye y define las periferias y el margen. Reconocemos que uno de esos espacios de marginalidad estaba localizado en el límite oriental de la ciudad, un lugar llamado "Aguas Negras". Las tensiones entre ambos territorios se dejaron sentir pues, como espacios identitarios, hubo un doble proceso de reconocimiento y desconocimiento de aquellos sujetos con los cuales se relacionaban.

En esta diversidad de culturas urbanas, la entronización de los postulados y comportamientos provenientes de las élites sociales y estatales fueron configurando, merced al control social por la coerción y la persuasión, un espacio urbano regulado. El disciplinamiento social se advierte cuando los "hábitos" impuestos por los grupos dominantes fueron legitimados por los subalternos, reconociéndolos como propios.

Por ello concluimos que el control social por el consenso, para cuyo logro la labor de la policía urbana fue decisiva, resultó exitoso en la ciudad de Concepción, a tal punto que la élite terrateniente, representada por la Sociedad Nacional de Agricultura, llegó a considerar la creación de una policía rural con el fin de controlar los campos. La eficiencia demostrada por la policía urbana, en cuanto a la modificación de conductas sociales, fue tal que hasta hoy se comprenden como virtudes cívicas las normativas impulsadas por las élites y resguardadas por ella. 